\title{
The Variation of Factor of Enhancement in Nucleation Rate with Electric Field for Water Vapour and Ice
}

\begin{abstract}
: the nucleation rate is the parameter to judge the effect of electric field on nucleation of water vapour and ice glaciation. In the presence of electric field the total nucleation is the sum of nucleation due to electric field and nucleation due to diffusion of water molecules. Thus we can say the nucleation rate is enhanced by the factor of $R_{E}$. This is known as factor of enhancement in nucleation rate. In the present work we will calculate the factor of enhancement in nucleation rate for water vapour and ice on temperature $268 \mathrm{~K}$ at different electric fields as a function of super saturation ratio.

Keywords: Enhancement Factor, Ice Glaciation, Nucleation Rate, Super Saturation Ratio.
\end{abstract}

Abhishek Kumar Mishra, Vikas Mishra higher about $10^{5}$.

\section{INTRODUCTION}

In The process of nucleation of water vapour, the small water drops sudden form the cloud. The nucleation rate $\mathrm{J}$ may be explained as the number of drops appearing per unit volume per unit time. It may also be explained as the rate of germ formation.

Pruppacher and Klett[1] obtain an expression for nucleation rate a

$$
J_{w}=C_{\text {Sat.w }} W \downarrow \Omega_{g} Z \exp \left[-\frac{\Delta G_{w}^{*}}{K T}\right]
$$

Where $\mathrm{Z}$ is zeldovitch factor, and $W \downarrow$ is the flux of water molecules to the germs.

The equation (1) only holds for non-spherical germs.For spherical germs the nucleation rate equation is given below.

$$
J_{w}=\frac{\alpha_{c}}{\rho_{w}}\left(\frac{2 N^{3} M_{w} \sigma_{w / v}}{\pi}\right)^{1 / 2}\left(\frac{e_{s a t . w}}{R T}\right)^{2} S_{v . w} \exp \left[-\frac{\Delta G_{w}^{*}}{K T}\right]
$$

Where

$\Delta G_{w}^{*}$ is the Gibb's free energy for formation of water germs or nucleus,

$\alpha_{\mathrm{c}}$ is the condensation coefficient,

$\rho_{w}$ is the density of water.

Wilson [2] demonstrated that the condensation may occurs without condensation centres like soluble and insoluble dust particles. He proposed that the condensation may occurs on ions. Bigg et al [3] and Bigg and Miles [4] indirectly supported the theory of ice formation on charged particle on the basis of his experiments.

Revised Manuscript Received on December 25, 2020.

* Correspondence Author

Abhishek Kumar Mishra*, Department of Physics, D B S College, C S J M University Kanpur, Uttar Pradesh, India, mr.abhishek1314@rediffmail.com

(C) The Authors. Published by Blue Eyes Intelligence Engineering and Sciences Publication (BEIESP). This is an open access article under the CC BY-NC-ND license (http://creativecommons.org/licenses/by-nc-nd/4.0/)
At the ground the concentration of cloud ice particles are lower while in upper and lower atmosphere it is sufficiently

Where $\quad \tau_{O N}=\frac{\tau_{0} \tau_{N}}{\tau_{0}+\tau_{N}}(5)$

is known as reduced relaxation time for electric field induced homogeneous nucleation.

The nucleation rate is enhanced by a factor $R_{E}$ is given by $R_{E}=\frac{J_{O N}}{J_{O}}$

$=\frac{\tau_{0}}{\tau_{O N}}(6)$

Substituting the value of $\tau_{O N}$ from equation (5) in equation (6).

$R_{E}=1+\frac{\tau_{O}}{\tau_{N}}$

$R_{E}=1+f(E)(7)$

Where function $f(E)=\mathrm{KE}$

with

$\mathrm{K}=2.128 \times 10^{21} \frac{T_{w} r_{w}^{* 1 / 2}}{\beta_{w}}$

for given temperature and radius of embryo.

By using equation (7) and (8) the calculated values of the factor of enhancement in nucleation rate with electric field as the function of supersaturation ratio for water and ice phase is shown in table-I and table-II.

Table-I Calculated Values of Factor of Enhancement for Nucleation Rate of Water Nuclei as a Function of Super Saturation Ratio at Temperature $268 \mathrm{~K}$

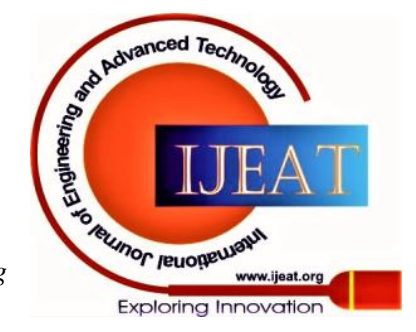


The Variation of Factor of Enhancement in Nucleation Rate with Electric Field for Water Vapour and Ice

\begin{tabular}{|c|c|c|}
\hline $\mathbf{S}_{\mathrm{v}, \boldsymbol{w}}$ & $\mathbf{E}$ & $\left(\boldsymbol{R}_{E}\right)_{\boldsymbol{w}}$ \\
\hline 1.001 & 2 & 7.0980 \\
\hline 1.002 & 4 & 9.6260 \\
\hline 1.003 & 6 & 11.5673 \\
\hline 1.004 & 8 & 13.2051 \\
\hline 1.005 & 10 & 14.6491 \\
\hline 1.006 & 12 & 15.9556 \\
\hline 1.007 & 14 & 17.1579 \\
\hline 1.008 & 16 & 18.2778 \\
\hline 1.009 & 18 & 19.3304 \\
\hline 1.010 & 20 & 20.3268 \\
\hline
\end{tabular}

Table-II Calculated Values of Factor of Enhancement for ice glaciation as a Function of Super Saturation Ratio at Temperature $268 \mathrm{~K}$

\begin{tabular}{|c|c|c|}
\hline$S_{v, i}$ & $\begin{array}{c}E \\
V / m\left(x \quad 10^{4}\right)\end{array}$ & $\left(\boldsymbol{R}_{E}\right)_{i}$ \\
\hline 1.001 & 2 & 5.8872 \\
\hline 1.002 & 4 & 7.9139 \\
\hline 1.003 & 6 & 9.4691 \\
\hline 1.004 & 8 & 10.7817 \\
\hline 1.005 & 10 & 11.9390 \\
\hline 1.006 & 12 & 12.9861 \\
\hline 1.007 & 14 & 13.9497 \\
\hline 1.008 & 16 & 14.8472 \\
\hline 1.009 & 18 & 15.6909 \\
\hline 1.010 & 20 & 16.4894 \\
\hline
\end{tabular}

And the variation of the factor of enhancement in nucleation rate with electric field as the function of supersaturation ratio for water and ice phase is shown in Figure 1 and Figure 2 respectively.

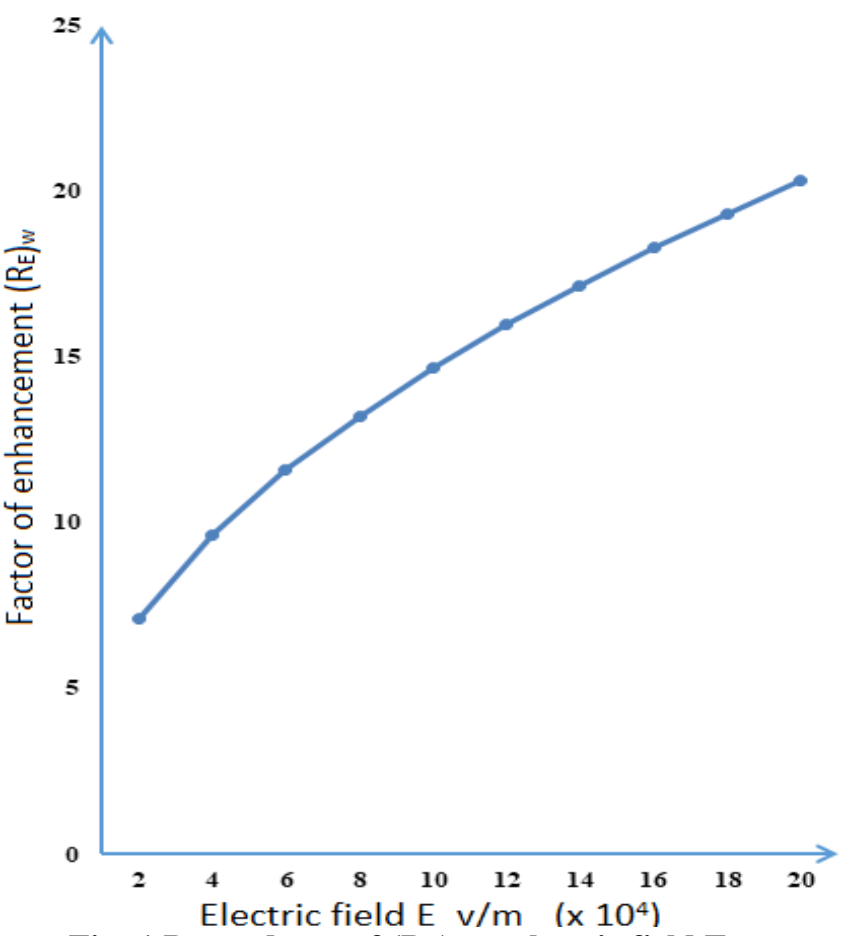

Fig.-1 Dependence of $\left(R_{E}\right)_{w}$ on electric field Eat temperature $268 \mathrm{~K}$ as the function of super saturation ratio.

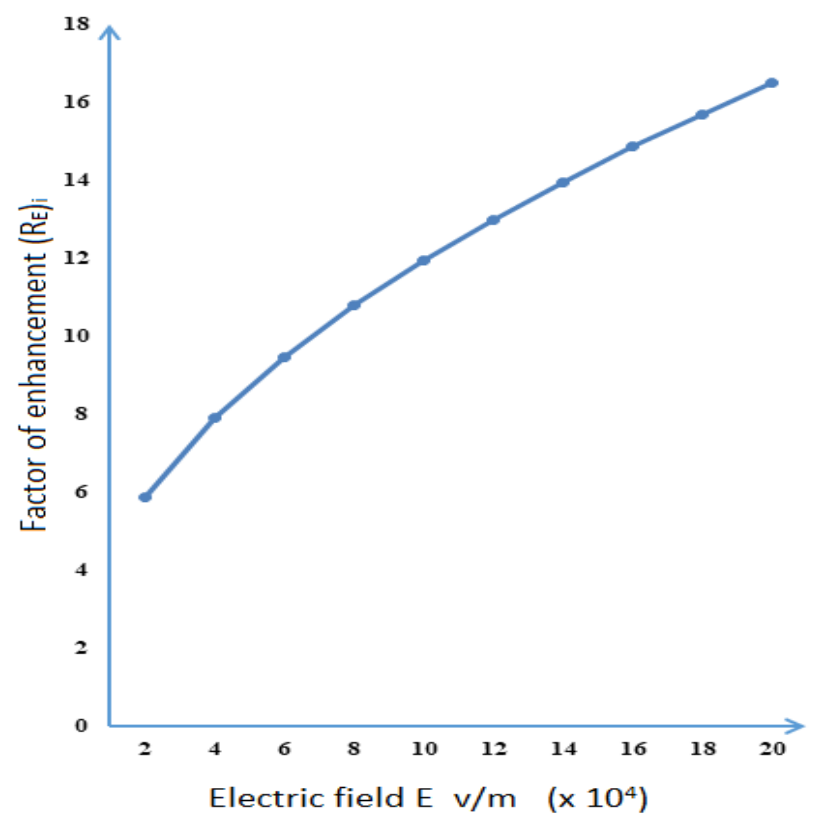

Fig.-2 Dependence of $\left(R_{E}\right)_{i}$ on electric field $E$ at temperature $268 \mathrm{~K}$ as the function of super saturation ratio

\section{RESULT AND DISCUSSION}

The rate of nucleation is very sensitive to super saturation ratio. The factor of enhancement for water vapour and ice nucleation is calculated by using equation (7) and (8) and shown in Table-I and Table-II respectively. In the presence of an external electric field the nucleation process is largely enhanced in condensation and glaciations.

Blue Eyes Intelligence Engineering and Sciences Publication

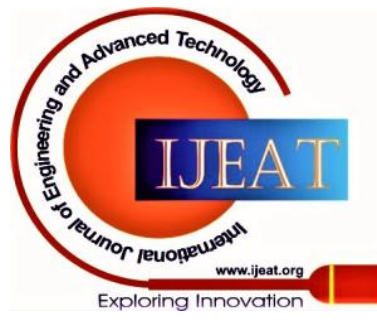




\section{CONCLUSION}

The present study provides a basis to conclude that the ions play an important role in cloud condensation and ice nucleation.The relaxation time is found to vary inversely with the externally applied electric field. In the presence of an electric field the relaxation time is very much lowered, at $273 \mathrm{~K}$ and for $\mathrm{E}=15 \times 10^{4} \mathrm{~V} / \mathrm{m}$. The relaxation time is lowered by about 82 times as compared to that in the electric field free homogeneous nucleation.

Thus from the Table and Figure we conclude that nucleation process is enhanced in the presence of an electric field and the enhancement depends linearly on the magnitude of the electric field.

\section{REFERENCES}

1. Pruppacher, H. R., and Klett, J. D., Microphysics of Clouds and Precipitation, D. Reidel Publishing Co., Dordrecht, Holland, 1980.

2. Wilson, C. T. R., Trans. Roy. Soc., A221, 73, 1920.

3. Bigg, E. K., Miles, G. T. And Hefferman K. J., Stratospheric ice nuclei, J. Meteorol., 18, 804-811, 1961.

4. Bigg, E. K., Miles, G. T., Stratospheric ice nucleus measurements from balloons, Tellus, 15, 162-166, 1963.

5. Israel, H., Atmospheric Electricity, Vol. 1, PP 129, Israel Program for Sci. Transl., Jerusalem, 1971.

6. Herman, J. R. And Goldberg, R. A., Sun, Weather and Climate, Nasa SP, 426, 1978

7. Scharrer, L., Kondensation Von Ubersattigten Damp Fen anIonen, Ann. D. Physik. 35, 619-639, 1939.

8. Singh, N., Rai, J. and Varshneya, N. C., Role of Ions on Relaxation Times in Nucleation Process, Nat. Acad. Sci. Lett., 7(12), 375-378, 1984.

\section{AUTHORS PROFILE}

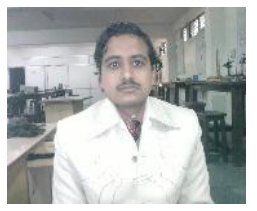

Abhishek Kumar Mishra,Ph. D. research scholar Department of Physics, D B S College, C S J M UniversityKanpur, Uttar Pradesh, India, mr.abhishek1314@rediffmail.com, Qualifications: M.Sc. (Physics), M.Phil. (Physics), B.Ed.Publications: 8 paper published in different journals.

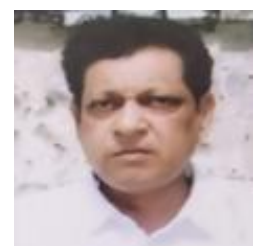

Vikas Mishra,Associate Prof. Department of Physics, D B S College, C S J M UniversityKanpur, Uttar Pradesh, India, vikasmishra1969@gmail.com, Qualifications: M.Sc. (Physics), Ph.D.Publications: 20 paper published in different journals. 6 research scholars have been awarded ph. D. Degree in physics and two researcher will submit their thesis in CSJM University before 15 January 2021 under my supervision. I am the member of IAPT. My research area is lattice dynamics and environmental physics.

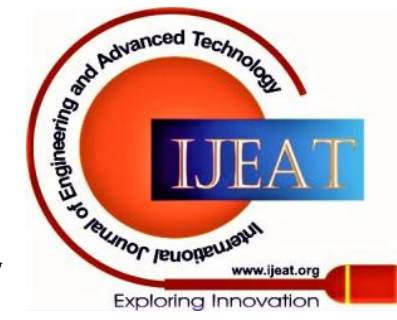

